\title{
Informal Logic \& the Surprise Exam
}

\section{Daniel H. Cohen}

Department of Philosophy

Colby College

Waterville, Maine, USA

dhcohen@colby.edu

The Paradox of the Surprise Exam can be an invaluable pedagogical vehicle for developing and deploying many of the relevant concepts of informal logic, argument analysis, and rudimentary philosophy of language. These include: the concepts of validity and soundness, and the differences between premises and conclusions, between inferences and implications, between logical entailment and pragmatic implication, and between assertions and other speech acts. Of most importance, the paradox also provides a good entry into the basics of the three main approaches to argument analysis: the logical, the rhetorical, and the dialectical. Along the way, the students will be introduced to reductio ad absurdum arguing, mathematical induction, and meta-reasoning. Finally, if the recommended resolution that is provided here is adopted, the treatment culminates in the neighborhood of Gödel's Incompleteness Theorem.

(C) Daniel H. Cohen 


\section{The Paradox}

Here is one version of the Paradox of the Surprise Exam ${ }^{1}$ : A teacher announces to her class that there will be an exam on one of the five days of the next week. Furthermore, it will be a surprise exam in that no one will be able to determine which day the exam will be prior to the day on which it is actually to be given. Were any students able to demonstrate that they have correctly inferred the day of the exam from anything the teacher says, the exam would have to be cancelled because it would not then be a surprise.

A clever student from the back of the room remarks to his classmates that at least they can be sure that the exam will not be on Friday. Either we will already have had the exam by next Thursday evening, he explains, in which case there will be no exam on Friday, or else we will not have had the exam by then, in which case we will all know it is coming on the following day - but that would be to no one's surprise. That would contradict the announcement, he concludes, so it would have to be called off.

The student next to him, who is a bit cleverer, agrees, and then points out that the exam cannot in fact be given at all! She begins her argument by noting that the surprise exam cannot be given on Thursday either. On Wednesday evening, she reasons, if we have not had the exam, then only Thursday and Friday would remain, and with Friday already eliminated, that means it would have to be Thursday - an inference which we are all capable of making. Similar reasoning, she concludes, eliminates each day of the week in reverse succession. Therefore, there cannot be a surprise exam on any day.

As the teacher is pondering their reasoning and nodding her agreement, a third student remarks that the other two students, having convinced themselves that no surprise exam can be forthcoming, are now quite ripe for a surprise! And any other students who accept their reasoning, could very well be in for a rude awakening some day next week. Even Friday is a possibility once we've convinced ourselves it is not. Maybe it's just that I'm overly cautious, he adds, but I can't bring myself to accept their conclusions. I don't know exactly what is wrong with their arguments, but I think there must be something amiss. In the end, that student was right: the exam was given on the following Thursday and everyone was caught quite by surprise.

W. V. O. Quine defined a paradox as, roughly, an apparently absurd conclusion supported by an apparently cogent argument, further dividing the field into "veridical" and "falsidical" paradoxes according to whether the conclusion is in fact true or false. ${ }^{2}$ The Surprise Exam fits snugly into the veridical mold: the story in which the exam is given counts is itself an argument to the curious conclusion that a surprise can be announced beforehand. 


\section{Conceptual Components}

Four parts have been separated in this version: (a) the teacher's announcement; (b) the argument against the last day; (c) the second argument eliminating the preceding days; and (d) the response, or meta-argument, as it were, resisting and countering the first two arguments. ${ }^{3}$. When presented this way, virtually all of the principle components of argumentation theory are readily distinguishable and available for inspection.

First, we can consider the matter from a narrowly logical perspective. That is, we can consider the students' arguments as proofs, and assess their validity and soundness, cogency or fallaciousness. There is an explicit premise - the teacher's announcement. There are several conclusions-Friday is not a possibility, no day is a possibility, every day is a possibility. And where there are proofs, there are inferences to evaluate: the Reductio ad absurdum by the first student, the mathematical induction by the second, and the meta-reasoning by the third.

One lesson that might be drawn from the first two students' arguments is that if the reasoning is valid, but the conclusion is false-the exam apparently can be given-then the premise must be faulty. The teacher has somehow contradicted herself, or possibly failed to make a genuine assertion. To draw this conclusion is to identify implicit, or enthymematic, assumptions, viz., that the teacher has asserted something and she can be trusted. ${ }^{4}$

There is the air of paradox, or even of self-contradiction, about announcing a surprise beforehand. The fact that the exam can be given to the students' surprise, as in the story, shows that everything the teacher said could turn out to be true, so there is no logical contradiction in the announcement. There is, however, something of a pragmatic contradiction: when a sentence, $p$, is asserted, there is the pragmatic implication - albeit not a logical entailment-that it has been asserted in earnest and that it is believed. The prior announcement of a surprise seems to violate, by implicature, the Gricean principle of quality. ${ }^{5}$

This points to a second, broader perspective: the rhetorical. While the teacher's announcement is not itself an argument that is intended to persuade or convince, it becomes part of rational-persuasion dialogues when the students appropriate it for use as a premise in their arguments. We can start by asking whether the statement announcing the exam was true or false. In the event, it turned out to be true, but was it true all along, or did it become true? Is the announcement best understood as a simple declarative statement? Or is it better heard as a declaration of intent, a prediction, or some other form of discourse that is unsuitable for use as a premise in argument? ${ }^{6}$ The teacher's statement belongs in the troublesome category of future contingents, but there are versions that manage to avoid the extraneous issues associated with them. There is, for example, a version involving a "Surprise Egg," an egg that is in one of ten boxes arranged in a row before us. The boxes are to be opened in sequence, with the information that we will not be able to figure out which box contains the egg before we get to it. ${ }^{7}$ While a surprise 
exam that has been slotted into a day on the calendar is not yet actualized, the egg in question is already palpably present in one of the boxes. (But which? Not the last one, surely. And since it cannot be in the tenth, it just as surely could not be the ninth...)

Third, we can consider the matter from a more dialectical perspective, focusing our attention on the exchanges between the teacher and the students, and between the first two students and the third. In particular, the exchange between the second and third students can be construed as an argument over a thesis (that the exam cannot be given) with a proponent (the second student), an opponent (the third), and an audience (the teacher and the other students). The third student's response is then seen as an objection. Their dialogue can be imaginatively continued: the second student might answer the third by admitting that his (meta) reasoning might be more practical. If we accept the conclusion that we cannot know the date of the exam beforehand, we will be motivated to study and be prepared each day. But if we accept her reasoning, then they will expect the exam and thus forestall it, by the stated condition that it be a surprise.

There are two very important points to make here. First, further extrapolation of their dialogue can be easily imagined. As a general rule, argumentation does tend to be open-ended in this way. Objections to arguments are often best construed as invitations to further dialogue. ${ }^{8}$ While the products of reasoning may be thought of as static proofs, argumentation itself is a process whose products are events with internal dynamics. Second, there are different audiences that might be targeted. Who is supposed to be persuaded: the other students (the exam can be given, so be prepared) or the teacher herself (the exam is expected, so it cannot be given, on pain of contradicting yourself)? One way to measure argument success is by whether the opponent is persuaded; a better way is by whether the target audience (which often includes the opponent) is persuaded.

\section{The Principle of Meta-Rationality}

The third student's argument is noteworthy because it is a meta-argument. His reasoning exemplifies the Principle of Meta-Rationality (PMR), viz., that part of reasoning rationally is reasoning about rationality. In particular, he uses a metaargument to reject the apparently good argument of his classmate: I don't know what is wrong with her argument, but the conclusion is unacceptable, so I will reject it on the assumption - or faith, perhaps - that there really is something wrong with it. In general, it may well be a sign of strength to bow before a good argument, ${ }^{9}$ but in some circumstances, it can also be a sign of strength to resist an argument-even a good argument!

To see exactly what goes wrong, consider the first student's argument, that Friday is out as a possibility. The reasoning is logically unimpeachable, but it can be challenged both rhetorically and dialectically. Suppose, to change the story a little, the teacher said, on Thursday, "Tomorrow you will have a test in one of your 
classes. It will be a surprise in that you will not know beforehand whether it will be in history, mathematics, or science-but it will be in science."

What can the students conclude? If they believe what the teacher says about the exam being a surprise, they cannot believe what she says about the subject being science. Conversely, if they believe what she says about a science exam, they cannot believe that it will be a surprise. If, as a result, they do not believe what she says at all, she can indeed give a surprise science exam, making her announcement true. But it is only true in retrospect. Its truth is contingent on the students not believing her! Her sentence, as a simple assertion, is true if and only if the students do not believe it. Thus, any argument they could construct that uses her assertion as a premise--which is to say, as implicitly accepted-would, ipso facto, be an argument with a false premise! However valid the argument may be, it cannot be sound.

Thus, the pragmatic contradiction noted earlier manifests in a Gödelian incompleteness result: the teacher's announcement is either an unbelieved truth or a believed falsehood, similar to the Gödel sentence that must be either an unprovable truth or a false theorem. In either case, the announcement is unavailable for use as a premise. That is to say, there is a rhetorical transgression committed by the teacher rather than a logical fallacy committed by the students. She has pretended to give them information they can use, but the communication was fraudulent. This was compounded by a dialectical offense, when, as in the original version, the teacher appeared to accept the first two students' arguments but then gave the exam-to their surprise-anyway.

\section{Conclusion}

In addition to all of the issues that can be raised in connection with the Paradox of the Surprise Exam, there is also a pedagogical benefit to be had from actually announcing (rather than merely considering or exploring) Surprise Exams: the heightened student anxiety that results is accompanied by a heightened level of daily preparation. There is also a significant price to be paid: the heightened level of daily preparation comes with that heightened anxiety, and the long term costs of that anxiety generally outweigh the short term benefits of the preparation. Different students respond differently, though, so this is commended as an area for further empirical investigation. 


\section{Notes}

'Also known as the Paradox of the Unexpected Hanging, this paradox appears in many versions. Even a partial bibliography would extend to several pages, and include the names of such distinguished philosophers and logicians as L. J. Cohen, W.V.O. Quine, M. Scriven, A.J. Ayer, D, Kaplan and R. Montague, K. Popper, F. Fitch, and J. Bennett. ${ }^{2}$ W.V.O. Quine introduces this terminology in the title essay of Ways of Paradox and Other Essays (Cambridge, MA: Harvard University Press, 1976).

${ }^{3}$ Generally, the paradox is presented as a story in which the exam is indeed given in the end. That stage has been preceded here by the fairly explicit meta-argument, the pedagogical purposes of which become clear.

${ }^{4}$ This is the gist of Quine's own solution in, "On a Supposed Antinomy," reprinted in Ways of Paradox and Other Essays.

${ }^{5}$ H.P. Grice, "Logic and Conversation," in Syntax and Semantics, vol. 3, P. Cole and I. Morgan, eds. (New York: Academic Press, 1975).

${ }^{6} \mathrm{G}$. Ryle's discussion of an argument for fatalism, "It Was to Be," the second lecture in Dilemmas (Cambridge: Cambridge University Press, 1954), might be a helpful supplement here.

${ }^{7}$ The Surprise Egg version appears, with several others, in Martin Gardner's The Unexpected Hanging and Other Mathematical Diversions (New York: Simon and Schuster, 1969).

${ }^{8}$ This is the point behind the claim that, ideally, "the charge of fallacy serves to extend the argument, not to cut off debate." R.H. Johnson and J. A. Blair, Logical Self-Defense (Toronto: McGraw-Hill Ryerson, 1977 ( $1^{\text {* }}$ ed.), p. 200.

${ }^{9}$ A.F. Snoeck-Henkemans, Poster for the 4th International Conference on Argumentation, International Society for the Study of Argumentation, Amsterdam, June 16-19, 1998. 